\title{
Monitoring Services to Support Continuous Curriculum Engineering
}

\author{
Peteris Rudzajs ${ }^{1 *}$ and Marite Kirikova ${ }^{2}$ \\ ${ }^{1}$ Alumni of Riga Technical University, Kalku iela 1, LV-1658, Riga, Latvia \\ ${ }^{2}$ Department of Artificial Intelligence and Systems Engineering, \\ Riga Technical University, Kalku iela 1, LV-1658, Riga, Latvia \\ Peteris.Rudzajs@edu.rtu.lv, Marite.Kirikova@rtu.lv
}

\begin{abstract}
Continuous and rapid developments in science and technology have raised a challenge for compliance between the learning content provided by study programs and (1) the actual state of art in the domains the programs are addressing and (2) the actual needs of companies that will employ the graduates of these programs. To achieve such compliance continuously, the digitalization of learning content (curriculum) engineering could provide supporting tools that facilitate awareness of incompliance, which is the first step in introducing changes in the learning content. In this article we discuss how such awareness, regarding the needs of companies, can be supported by a service system that monitors the gap between educational demand and offer. The proposed service system provides possibilities for automatic, semi-automatic and manual analysis of texts representing the educational demand, versus the texts representing the educational offer. The implementation of the service system has been demonstrated, having been applied at university. The experiments showed that the system can provide valuable information for educational content development, but its maintenance and incorporation in study process management and curriculum engineering still require additional research.

Keywords: Educational Content, Monitoring System, Service System, Content Engineering, Curriculum Engineering, Continuous Engineering.
\end{abstract}

\section{Introduction}

Global connectivity, advances in technology, and the necessity to adapt to unpredictable circumstances, have exposed a complexity of enterprise operation which calls for continuous enterprise engineering [1]. Curriculum development and maintenance can be viewed as a specific enterprise in an educational domain, which faces the same challenges as any other enterprise operating in a global environment. Therefore, the use of engineering methods can also be applied in this domain. There have been many attempts made in achieving curriculum development

\section{*Corresponding author}

(C) 2021 Peteris Rudzajs and Marite Kirikova. This is an open access article licensed under the Creative Commons Attribution License (http://creativecommons.org/licenses/by/4.0).

Reference: P. Rudzajs and M. Kirikova, "Monitoring Services to Support Continuous Curriculum Engineering," Complex Systems Informatics and Modeling Quarterly, CSIMQ, no. 29, pp. 53-73, 2021. Available: https://doi.org/10.7250/csimq.202129.04

Additional information. Author ORCID iD: P. Rudzajs - https://orcid.org/0000-0002-7377-5996, M. Kirikova https://orcid.org/0000-0002-1678-9523. PII S225599222100166X. Received: 15 November 2021. Accepted: 23 December 2021. Available online: 31 December 2021. 
(engineering) continuity by utilizing data from learning management systems [2]. Such approaches help to adapt the teaching process to the needs of students. However, the needs of employers, who expect concrete competences form the graduates, are not less important in achieving success in curriculum execution. In this regard, the content of curricula has to follow the rapid and continuous changes in the social environment. The scope and complexity of that change calls for the use of artificial intelligence tools in curriculum engineering. In [3], the authors use a back propagation method to see whether a curriculum meets the competencies expected by the industry. The method assumes that the skills needed are known, however, as mentioned above, the needs are continuously changing, and the opinions gained at the beginning of an experiment can be already outdated after a short period of time (e.g., in six months).

In this article we focus on curriculum engineering in university education in the area of computer science and information technology, where the learning content is expected to continuously comply to both (1) the state of art in science and (2) current industrial needs, despite rapid changes in science and industry. A similar situation might also be observed in other areas of education but their analysis is beyond the scope of this article. The scope is limited, also, to industrial needs only, and does not consider the compliance between the state of art in science and university curricula.

For supporting continuous curriculum engineering, we propose an approach that uses available evidence from internal and external information sources for monitoring the gap between the required competences (further referred to as "educational demand" and abbreviated as "edu d") and the competences a curriculum can provide (further referred to as "educational offer" and abbreviated as "edu o"). If the gap is not monitored, it can increase, thus causing economic slowdown, employment problems, and other inconveniences [4]-[7]. To achieve and maintain the compliance between edu $\mathrm{d}$ and edu $\mathrm{o}$, it is necessary to identify and process the sources of information that can characterize the edu $\mathrm{d}$ and $\mathrm{o}$ at chosen points of time. For gathering data about edu $\mathrm{d}$, such information sources as job advertisements, job descriptions, the results of surveys, professional standards, curriculum recommendations, and professional bodies of knowledge can be used [8]. For gathering data about edu o, study programs, and course descriptions can be used as primary sources of information. Continuous monitoring of both the edu $\mathrm{d}$ and edu o, would give an opportunity to timely change the curriculum content and teaching methods in order to achieve the continuous compliance of the demand and offer.

The rest of the article is structured according to the design science research life cycle [9]. Problem identification, motivation, and objectives of a solution are discussed in Section 2. The design of monitoring services is presented in Section 3. Demonstration and evaluation of the services is provided in Section 4, The discussion and conclusions are given in Section 5.

Separate details of this research have been already gradually published in [8] and [10]-[22] along with the more than five years long concept and software development process. This article gives a holistic view on the research work done and adds the experience of the use of the monitoring services after putting them into the operation. To shorten the phrase "compliance between edu $\mathrm{d}$ and edu o", the abbreviation edu $\mathrm{d} / \mathrm{o}$ will be used in the remainder of the text.

\section{The Need and Possibilities for Monitoring the Educational Demand and Offer}

The problem to be solved will be illustrated here in the context of enterprise engineering [23] viewing curriculum development and execution as an enterprise. While the need for continuous improvement and, thus, engineering of enterprises has been well recognized ${ }^{\dagger}$, practical implementations of continuous engineering are reported mainly in the domain of information technologies, where the software product should continuously comply with the ever-changing

\footnotetext{
$\dagger$ Workshops, Tutorials and Working Session Program | PoEM 2021, November 24-26 (rtu.lv)
} 
needs of a business. Nevertheless, in general, the very aim of continuous engineering enterprise wide is the compliance between user expectations and products and services provided [24]. When projecting this to curriculum engineering, we arrive at the purpose to have a curriculum which can continuously comply to the needs of industry. One of the essential problems in achieving this purpose is the need to continuously be aware of this compliance respecting the globally changing stakeholder needs for education and, also, respecting internal, bottom-up, changes in the curriculum introduced in actual delivery of subjects that belong to it. The problem addressed in this article is illustrated in Figure 1: it is a lack of means to continuously monitor the compliance between the educational demand (edu d) and educational offer (edu o).

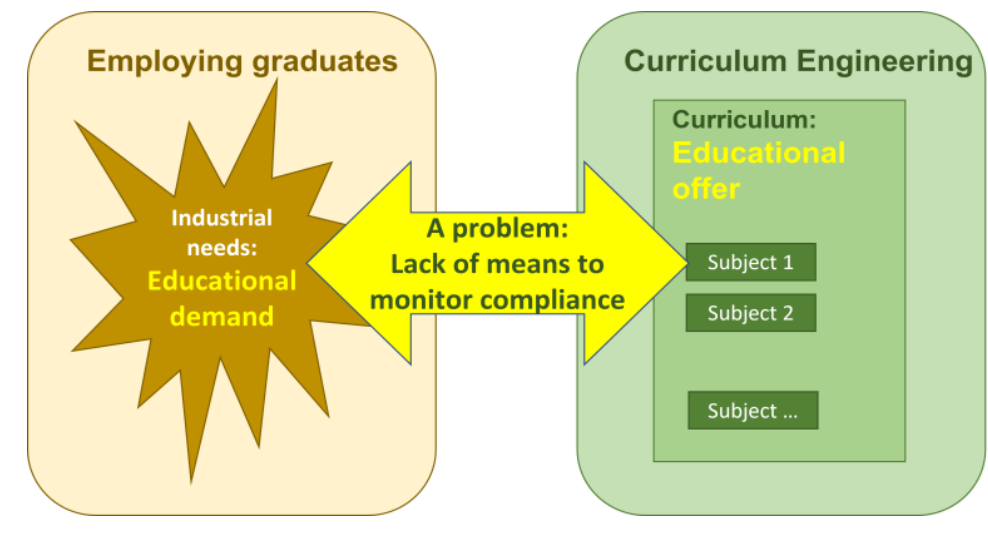

Figure 1. Research problem: how to support continuous awareness of the compliance between educational demand and educational offer in curriculum engineering

We assume that most of the information that can be used for comparison of edu $\mathrm{d}$ and edu o is represented in different documents that are available internally in a university (or other educational institutions or units) and on the Web, or in other available storage facilities. We refer, in this article, to the document as a representation of information, e.g., a curriculum, as a document, represents information about study courses included in it. A course description is also a document representing, among other issues, offered knowledge, e.g., in terms of learning outcomes. Similarly, job advertisements by a company, constitute a set of documents representing educational demand. Other essential sources of information can be industrial bodies of knowledge, certification requirements and industrial standards. The above-mentioned information sources (documents) comprise an amount of information which is hard to check and analyze both manually and frequently, because they are continuously changing, are available in very different formats (knowledge, skill, and competence information can be encoded in unstructured, semi-structured or structured textual documents), and are distributed across different locations such as the World Wide Web, databases, and other document storage facilities within organizations [8]. The multidimensional heterogeneity of documents to be considered is a challenge that should be addressed by the proposed solution for the edu d/o monitoring.

Edu d/o information monitoring would provide valuable information to stakeholders both from education institutions (teachers, study program directors, and students, etc) and industrial organizations (employers and employees). These stakeholders can be involved in information processing activities related to edu $\mathrm{d} / \mathrm{o}$ information processing. To continuously analyze edu $\mathrm{d}$ and edu o compliance, the monitoring results and related information, including source documents, should be made available to different groups of stakeholders. Due to the different approaches in maintaining edu $\mathrm{d} / \mathrm{o}$ information sources, different implementations of the information acquisition methods should be available in edu $\mathrm{d} / \mathrm{o}$ information monitoring. For instance, course descriptions at universities usually are maintained and stored in databases which enables automatic acquisition of edu $\mathrm{d} / \mathrm{o}$ information. As employers usually maintain their job advertisements in Web sites, special mechanisms are required to make these descriptions available to other stakeholders, e.g., descriptions could be made available via dedicated 
interfaces or using Web crawlers [25]. In some cases, the human actor's involvement might be necessary to feed the monitoring solution, while in other cases, information could be obtained and provided for further analysis without the involvement of a human actor. Diversity of stakeholders also is a challenge in edu $\mathrm{d}$ and edu o compliance monitoring.

This diversity of stakeholders is complemented by one more challenge: several variants of potential roles of a stakeholder with respect to the monitoring solution. To characterize the human actor involvement, the term automation level is used. The following automation levels are assumed: manual, automatic, and semi-automatic. The manual level stands for an activity that is performed by a human actor (perhaps, by using some general purpose office software, but not by the dedicated software application); the automatic level refers to an activity that is performed by a dedicated software application without the involvement of a human actor; and the semiautomatic level refers to an activity that is performed by the dedicated software application, where some human actor involvement is necessary, e.g., a human actor should review and adjust the results obtained by a software application.

Respecting the above-mentioned challenges, the following research goal was formulated: To develop the edu d/o monitoring system's model by satisfying the following requirements:

- Req. 1: processing edu d/o information with various characteristics (multi-dimensionally heterogenous information);

- Req. 2: involving different types of stakeholders in the system's operations;

- Req. 3: supporting different levels of automation for the monitoring system's activities.

To fulfill the research goal, the following tasks were defined and performed:

1. To explore solutions for the information source maintenance, structured representation, retrieval, and analysis regarding the information sources relevant for edu d/o.

Information sources in the World Wide Web and inside the organizations, can be processed using software solutions, e.g., when gathering the Web content, recommender systems, data mining, and other solutions [26] can be used. Information processing usually consists of activities that can be classified in four main groups, namely, information acquisition, analysis, decision making, and decision implementation [27]. The automation of these activities can reduce their execution time thus speeding up the achievement of information processing goals. However, in practice, the full automation of activities is not always necessary or possible [28], thus leading to the situation where the activities have different automation levels in information processing [29]. The necessity for different levels of automations applies also to edu d/o information source maintenance, structured representation, retrieval, and analysis. For this purpose, such solutions as study management systems for maintenance of study course descriptions [30], [31], human resource management systems [32], and job advertisement portals (e.g., Https://www.cv.lv) for maintenance of job descriptions and advertisements are used.

For monitoring purposes, besides the maintenance of edu $\mathrm{d} / \mathrm{o}$ information sources, the processing of these information sources, should be performed. To automate the processing of the sources and to facilitate the common understanding between the stakeholders about the edu $\mathrm{d} / \mathrm{o}$ information represented in these sources, specific knowledge structures (structured representation of knowledge) can be used. Knowledge structures [33] systemize the concepts of a field of interest (e.g., knowledge, skills, and competences in information technology) and provide the means to represent edu d/o information in a structured way. Knowledge structures are suitable for achieving information interoperability [35], [36] between stakeholders and can serve as a "unified language" [34], which is understood by stakeholders. We found and experimented with several knowledge structures for representing knowledge, skills, and competences, e.g., "Computing Classification System" taxonomy provided by the Association for Computing Machinery (ACM-CCS) [37], European Dictionary of Skills and Competencies (DISCO) [38], European e-Competence framework (e-CF) [39], and tools and technologies 
defined by the American Occupation Information Network program "O*NET" [40]. A detailed description of the use of these knowledge structures for edu d/o monitoring is described in detail in [10]-[14].

As the edu d/o information sources are distributed and maintained by their owners, solutions are necessary for gathering them into one location to enable further analysis. As most edu d/o information sources are available on the Web, it is important to note the role of Web crawlers [25] for information retrieval. When information source documents are retrieved, usually analysis is performed to extract the concepts of interest (e.g., persons, locations, events, skills etc. [41]) from these documents. The most popular platforms for this purpose are Apache Unstructured Information Management Architecture (UIMA) [42] and General Architecture for Text Engineering (GATE) [43], which are used in various solutions, e.g., for the extraction of competence information from the employee profiles inside an organization [44].

\section{To explore the structural characteristics of monitoring systems.}

The main goal of a monitoring system is to provide the ability for a system's users to observe a situation and its changes during a period of time [45]. Monitoring systems in education and other domains were studied in this research, with the goal to find a foundation for edu d/o information monitoring solution development, namely, for the potential monitoring system's structure.

Monitoring systems are used in many domains, e.g., environment monitoring [46], health monitoring [47], mechanical systems monitoring [48], information technology infrastructure monitoring [49], media monitoring [50], [51], business activity, and process monitoring [52]. Monitoring systems in the education domain are used mainly for education management solutions that ensure the monitoring of the execution of study plans [53]-[55]. For the purpose of obtaining a common description of monitoring systems, we designed a description framework, which is available in [15] and [56]. The parameters included in the framework are marked in italics in the further description in this paragraph, where the projection of generic monitoring systems parameters onto edu d/o monitoring is described. In edu d/o information monitoring, the object of monitoring is textual edu $\mathrm{d} / \mathrm{o}$ information sources, which contain unstructured, structured or semi-structured (data rigidity) textual documents (data source format) generated by human actors. The monitoring aspect is edu d/o information represented in documents. Data are provided by virtual sensors (software retrieves the data from data sources) or physical sensors (human actor retrieves the data). In edu d/o information monitoring (similar to media monitoring systems) [57], the following monitoring sub-functions are relevant: information retrieval, analysis, and distribution. Data reading from data bases, Web crawling, data downloading, and manual data entry into the system are the monitoring methods used in the information retrieval subfunction. As edu d/o information source document analysis is a text analysis task, the information analysis sub-function includes natural language processing, namely, text analysis and concept based (i.e., using knowledge structures [10]) information source processing and mapping. For the information distribution sub-function, similar to other monitoring systems, specialized user interfaces and portals with search and browsing facilities can be used. Human actors and software can be involved in the execution of monitoring sub-functions (involved agents).

The framework developed for describing monitoring systems helped us to see that the edu $\mathrm{d} / \mathrm{o}$ monitoring system should include the characteristics of several types of monitoring systems, namely, be able to retrieve data form different types of data sources, because there are multiple edu d/o information sources, each with its characteristics; be able to handle structured, unstructured and semi-structured data, because edu d/o information is represented in different textual documents (unstructured, semi-structured, and unstructured); should include multiple elements and methods used in internal organization of monitoring systems for data retrieval, analysis and distribution, because different methods and elements are necessary to process edu $\mathrm{d} / \mathrm{o}$ information sources and to achieve the stakeholder goals; both human actors and software should be involved in monitoring data retrieval, analysis, and distribution, so that activities can be performed by human actors, software or both, depending on the needs of continuous 
curriculum engineering. The spectrum of identified characteristics gave evidence that the edu $\mathrm{d} / \mathrm{o}$ monitoring system should be developed as a service system.

\section{To explore the principles of service systems and service composition that are suitable for developing edu d/o monitoring solution.}

The solutions for edu d/o information source maintenance, retrieval, and analysis can be viewed as services, which, together with available resources (edu d/o information sources and knowledge structures), form a flexible system, which fosters the achievement of goals of stakeholders that are involved in continuous curriculum engineering, and also other stakeholders that could use the results of edu d/o monitoring (e.g., students choosing the courses, employees selecting the subjects for their enterprises, etc.) Therefore, the edu d/o monitoring can follow the paradigm of service systems that is focused primarily on interaction between people, technology, and other internal and external service systems, as well as on the exchange of shared information between the stakeholders of service systems in order to achieve common goals by service compositions [58]. A service is the base unit of a service-oriented solution and the service orientation principles are applied in its design [57]. Services, in a broader sense, are understood to be activities performed for the benefit of a service system's stakeholders [59]. However, in this article, services are understood simply as modular functionality that can be accessed and combined with other functionalities [60]. If the software is involved in the execution of a functionality, the term automated service is used. According to automation levels, a service can be with automation level "automatic" or "semi-automatic". If a human actor performs the functionality, the term manual service is used (automation level is "manual"). If the service is considered at a high abstraction level, then the term "abstract service" is used, whereas at the low abstraction level the term "concrete service" is used [61]. A concrete service is the implementation of an abstract service. Automated services and manual services are types of concrete services.

Respecting multiple types of information sources and different stakeholders involved in edu $\mathrm{d} / \mathrm{o}$ monitoring, and the necessity of considering the services with various automation levels, service composition in a service system requires handling a high level of variability.

4. To explore the principles of service systems and service composition that are suitable in development of an edu d/o monitoring solution.

Many systems are designed with variability in mind, e.g., self-adaptive systems, open platforms, as well as service systems [62]. The possibility of multiple edu d/o information management solutions (i.e., services) and their combinations (i.e., service compositions) for the achievement of stakeholder goals, necessitates the system's variability handling [63]. Different means for variability representation [64] and its incorporation in systems' architecture [65] are known. Variability in software engineering usually is defined as an ability for software or a software artifact (e.g., service) to be changed for the specific context [66], [67]. As the monitoring system is an information intensive system [68], the variability is defined as an ability to change an information processing unit (i.e., service) to adapt to the specific context or intention.

Feature models are widely used as the means to represent functional variability [64], [69]. Feature models are applied to manage a system's variability; to document and analyze mandatory, non-mandatory and alternative features of a system; to ease the communication of a system's features to stakeholders; and for the system's design [70], [71]. When representing system architectures, the architecture views, which are defined by viewpoints, can be used for variability handling [72]. Thus, a feature model is suitable for representing the view of a service system's functional variability [73]. As the behavior of a service system is determined by service compositions, the service flows (i.e., the result of service composition) are suitable for representing the view of a system's behavioral variability. To accommodate, in the feature model, all parameters required for the monitoring system, two methods were proposed, namely, the method for the design of the feature model extended with service types and automation levels, and the method for the design of service flows extended with service types and 
automation levels based on the feature model. These methods are discussed in the further sections of this article.

5. To develop an edu d/o information monitoring system model which represents the variability of the system's functionality and behavior. The proposed model is presented in Section 3 of this article.

6. To evaluate a proposed model by implementing a prototype. The implementation and evaluation of an edu d/o monitoring system's model is provided in Section 4 of this article

Thus, the main results of fulfillment of tasks 5 and 6 are represented by a generic edu d/o monitoring system's model (further in the text, the Generic Edu d/o information MONitoring system is referred to as GEduMON), and its implementable instantiation (EduMON), respectively.

\section{Generic Edu d/o Monitoring System's Model (GEduMON)}

The generic edu d/o monitoring system's model is a conceptual model defining the structure, behavior, and other aspects of the system [74]. It can be considered as the system's architecture because the architecture description is the representation of a system, allowing reasoning on the structure and behavior of the system. The developed generic edu d/o monitoring system's model is represented by mutually related sub-models. For simplicity, the GEduMON model is further referred to as the system's architecture, whereas the sub-models - as models constituting the architecture.

GEduMON architecture is developed in two levels, namely, general architecture and detailed architecture. General architecture defines the framework for the functional structure and behavior, whereas detailed architecture, based on the general architecture, defines functional structure and behavioral variability of the views.

GEduMON architecture is represented in Figure 2 and consists of the following components:

1. Base service model for the representation of architecture framework (Section 3.1).

2. Base service flow model for the representation of base service execution sequence, based on base services (see Section 3.2).

3. The architecture view for the representation of variability of system's functional structure based on the base service model using extended feature model (Section 3.3).

4. The architecture view for the representation of variability of system's behavior based on the view of system's functional structure using the representation of extended service flows (Section 3.4).

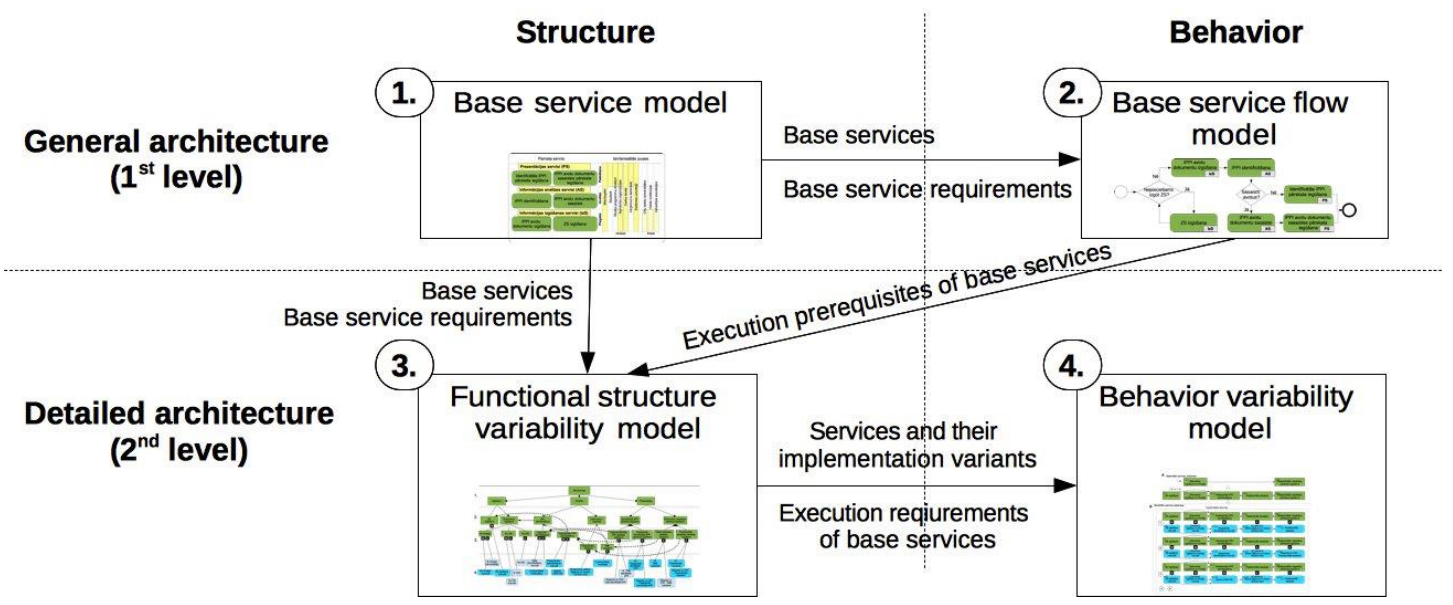

Figure 2. GEduMON components 
The components of the architecture were developed gradually. The base service model has been tailored to different use scenarios of the monitoring system that go even beyond continuous curriculum engineering (for instance, the use of the system for selecting subjects by employers was considered). Different aspects of this model are described in detail in [8], [10], [11], [14], [16], and [17]. The variability aspects of a system's functional structure and its behavior initially were discussed in [18]-[22].

\subsection{Base Service Model}

This section describes the GEduMON base service model (component 1.) of the general GEduMON architecture. The model is developed respecting the potential goals of different stakeholders that might be either involved in edu $\mathrm{d} / \mathrm{o}$ information monitoring or might be interested in the use of monitoring information. The base service model represents generic services required for edu d/o monitoring (see Figure 3 ).

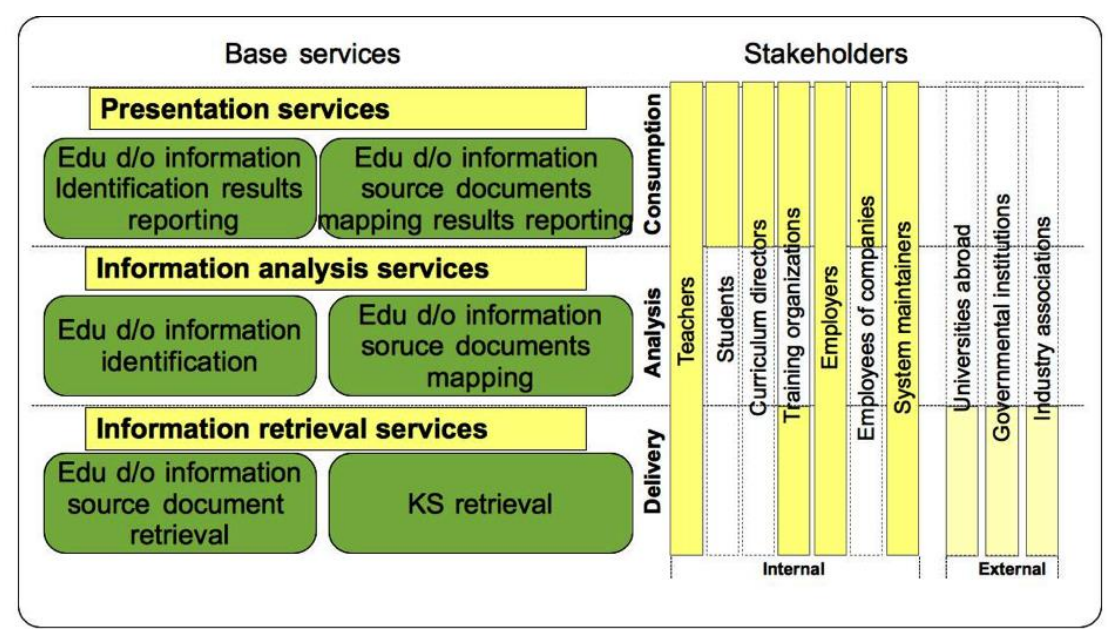

Figure 3. Base service model. Highlighted parts of the stakeholder bars point to the stakeholder involvement in execution of information delivery, analysis, and consumption (usage) activities.

The base services are represented as three service groups (retrieval, analysis, and distribution services):

- The group of information retrieval services. The services of this group are designated for delivering source content for analysis and distribution between the stakeholders and/or other services. Two base services belong to this group, namely, edu d/o information source document retrieval service and knowledge structure (KS) retrieval service.

- The group of information analysis services. The services in this group are designated for the identification of edu $\mathrm{d} / \mathrm{o}$ relevant data in documents and for comparing edu $\mathrm{d}$ and edu o documents. The direct and knowledge structure mediated comparisons (mappings between edu $\mathrm{d}$ and edu o) are possible and are proposed and discussed in [16] and [17]. The services of this group use the results obtained from information retrieval services.

- The group of presentation services. The services in this group are designated for the representation of analysis results to the stakeholders in the forms of tables, graphs, and images. Two base services belong to this group, namely, the service reporting results of edu $\mathrm{d} / \mathrm{o}$ information (relevant data) identification and the service reporting the results of document mapping (comparison).

Three types of requirements were specified to identify the service necessity, possible variations, and execution sequence: mandatory requirements ultimately to be fulfilled for achievement of stakeholder goals (e.g., continuous availability of information about edu d/o); 
possible variation requirements defining possible variants of base services; and service execution requirements defining the execution prerequisites of base services and their variants.

The potential involvement of stakeholders in the execution of services is represented at the right side of Figure 3. We can see that the largest involvement is expected in the consuming activity. But, to perform this activity, the retrieval and analysis activities should be performed. Stakeholder involvement in edu $\mathrm{d} / \mathrm{o}$ monitoring activities determines the involvement of stakeholders in EduMON base services, e.g., teacher involvement in analysis activity, which means that the teachers could be involved in the execution of EduMON base services aiming at edu $\mathrm{d} / \mathrm{o}$ information identification and edu d/o information source document mapping.

\subsection{Base Service Flow Model}

Based on requirements stated for the base services, the base service flow model was constructed for achieving the stakeholder goals (Figure 4). This model represents the monitoring system by abstracting from the variability of the system's behavior.

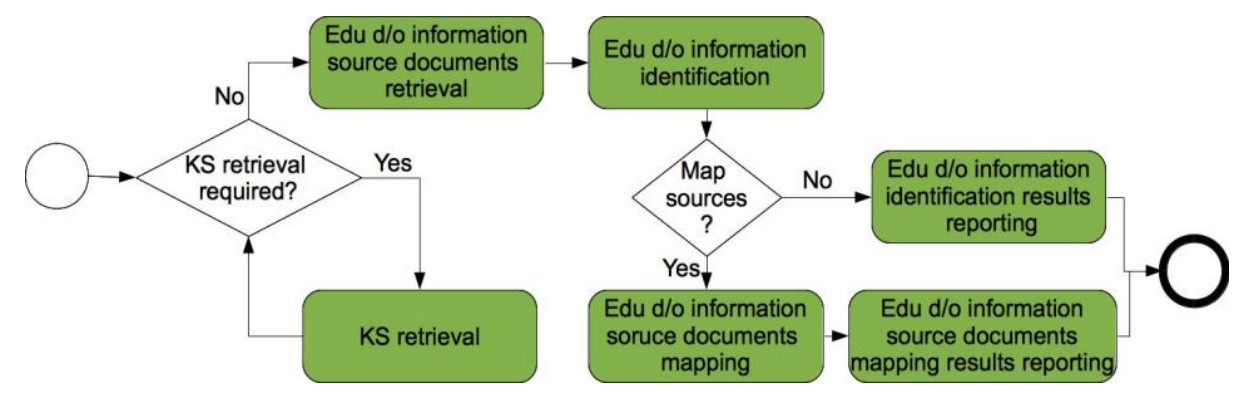

Figure 4. GEduMON base service flow model

Each service in the flow model can be executed only if the necessary resources exist, namely, the documents or knowledge structures are reachable; or the inputs that are the results from the execution of other services are available. Variability in the GEduMON base service flow is possible. Besides the variants of each base service, the implementation variants exist as well. Therefore, the GEduMON base services flow can have multiple alternatives, which are determined by the flows of service implementations or concrete services. To define concrete service flows, the view of variability of the system's functional structure, in the architecture, was defined, based on which method for service composition was proposed (these are described in Section 3.3 and Section 3.4).

\subsection{Functional Structure Variability Model}

For the representation of variability in the edu $\mathrm{d} / \mathrm{o}$ information monitoring service system, the extension of a feature model was proposed that enables the showing of abstract services, namely, service groups (i.e., variation points) and corresponding to those services (i.e., variants), as well as the concrete services or implementation variants of abstract services, which are characterized by automation levels. The developed feature model is described in detail in [21] and [22].

Abstract services in the feature model are represented as variation points in rectangular boxes, whereas the concrete services are represented as rounded boxes (Figure 5). The variation point is the point in the system where the choices have to be made as to which variants to use [67]. A variant is an option in the variation point. Concrete services implement abstract services, therefore, they are called "implementation variants of services". Abstract services are denoted as $S_{i}$, whereas concrete services as $S_{i} i^{\{A, M, S A\}}$, where the upper index points to the service automation level. Both for abstract and concrete services, the bottom index is used for identifying the number of a service.

The main benefits of the feature model, extended by service types and automation levels, are the following: (1) the possibility, even before service composition, of clearly identifying services 
where human actor involvement is necessary (namely, services with M and SA automation levels in Figure 5) and (2) the possibility, in service composition, of identifying the transition between services with different automation levels.

Using the extended feature model, a viewpoint [73] for variability of the system's functional structure is defined. Based on this viewpoint, the appropriate view of GEduMON is developed. The viewpoint also defines service relationships with other models in the monitoring system's architecture. Thus, the relationships with the GEduMON base service model are identified, meaning that the abstract services of the feature model should correspond to the GEduMON base services and their variants.

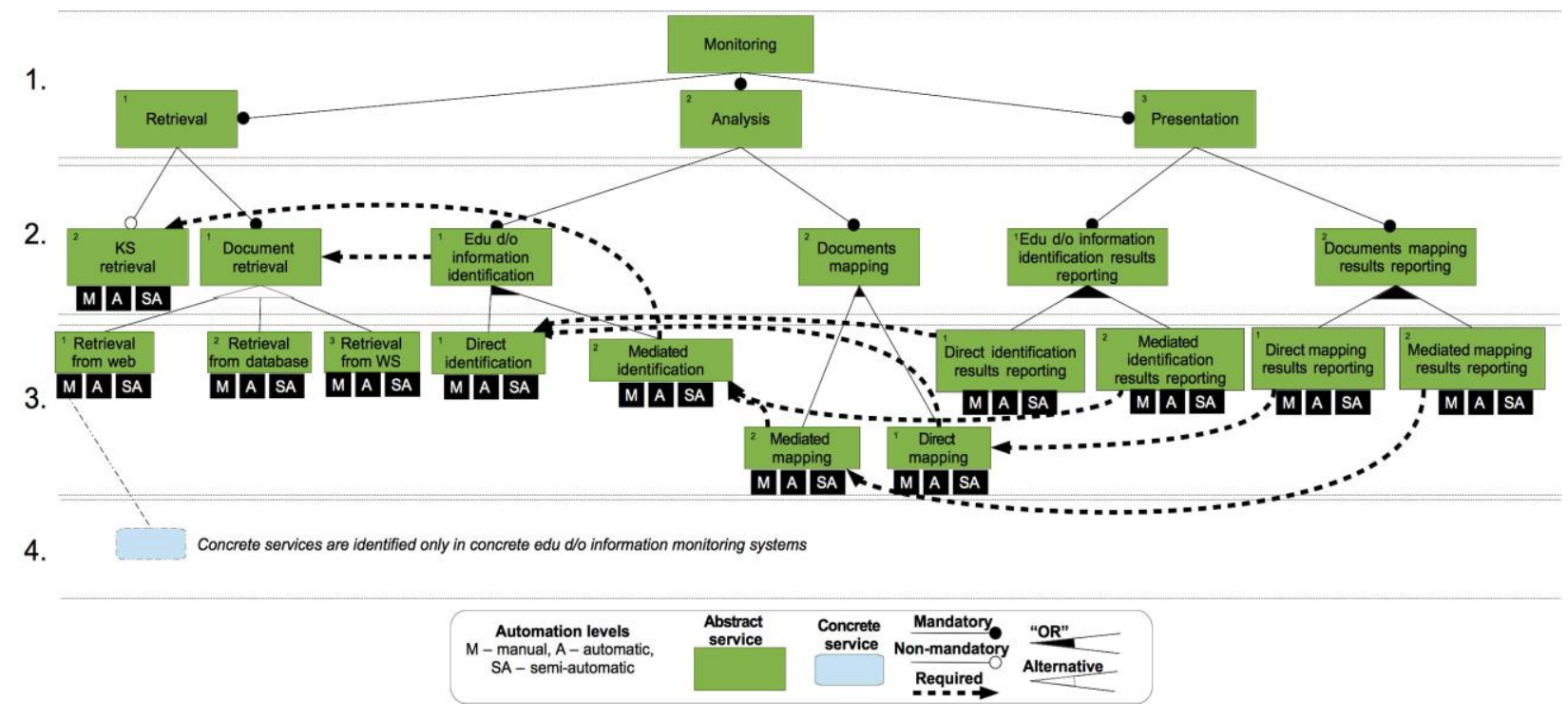

Figure 5. Feature model representing the view of GEduMON functional variability. 1. - service group level, 2. - base service level, 3. - base service variation level, 4. - implementation variants level.

\subsection{Behavior Variability Model}

Based on the general GEduMON architecture (the 1st level in Figure 2), the detailed architecture consisting of models of functional structure (discussed in Section 3.3) and behavior variability was developed. This section presents the behavior variability model, the goal of which is to specify the system's behavioral variability in alignment with the functional structure variability model. The service flows extended with service types and automation levels are used to define the viewpoint and the corresponding view for the variability of the system's behavior. In this viewpoint the relationship to the GEduMON functional variability model is identified meaning that the abstract services and concrete services of service flows correspond to the abstract and concrete services and the relationships presented in the GEduMON feature model. The Intention Oriented Service Composition (IOSC) method was proposed for the alignment of the system's functional structure variability with the system's behavioral variability (this method initially was presented in [21]). The IOSC method is applicable for service composition (i.e., the arrangement of services in the service flow) using the extended feature model, namely, its abstract and concrete services and the relationships between them. Thus, the extended feature model (discussed in Section 3.3) should be available to create concrete service flows for implementation of an intention-oriented service. The result of the usage of the IOSC method in GEduMON, allows us to analyze the system from the behavior variability viewpoint, by providing the ability to compose flows of services with various automation levels. By analyzing service flows we can directly identify the transitions and alignment of service interfaces, which is important when deciding on implementation of services and transitions between them. 
The next section discusses concrete implementations of the GEduMON model, namely, a software prototype presented as the EduMON portal used at a university. For implementation purposes, the GEduMON functional variability model was extended with concrete services and the IOSC method was used to construct the concrete service flows, implementing intentionoriented services, which constitute the monitoring system's behavior variability model.

\section{Implementation and Evaluation of the GEduMON Model}

This section demonstrates the GEduMON service groups by implementing them in a portal that is used for monitoring edu $\mathrm{d}$ and edu o (sub-Section 4.1). The section also provides a brief evaluation of the results of implementation (sub-Section 4.2) and gives a retrospective consideration about the use of the implementation in years 2015-2021.

\subsection{Implementation}

The GEduMON model presented in the previous section was defined as the architecture of a two level edu d/o information monitoring system. The system's general architecture (the 1st level in Figure 2) consists of the base service model and the base service flow model. The system's detailed architecture (the 2nd level in Figure 2) is based on the general architecture and consists of the functional and behavioral variability models. According to the developed GEduMON functional structure and behavior variability models, the abstract services were implemented and integrated in a unified system EduMON, thus, demonstrating the viability of service composition and promoting the tackling of edu $\mathrm{d} / \mathrm{o}$ monitoring problems.

Manual services were implemented as manually executable activities, the results of which were made available for other services in the monitoring system, by entering these results into the data base through the user interface input forms or by transforming them to formats acceptable of the system's other services. Automatic services were implemented as software components, integrated libraries or as integrated services provided by third-party service platforms.

The GEduMON functional structure variability model presented in Section 3.3 was extended with concrete services, thus obtaining the functional variability model. This model, implemented as EduMON portal, is represented in Figure 6.

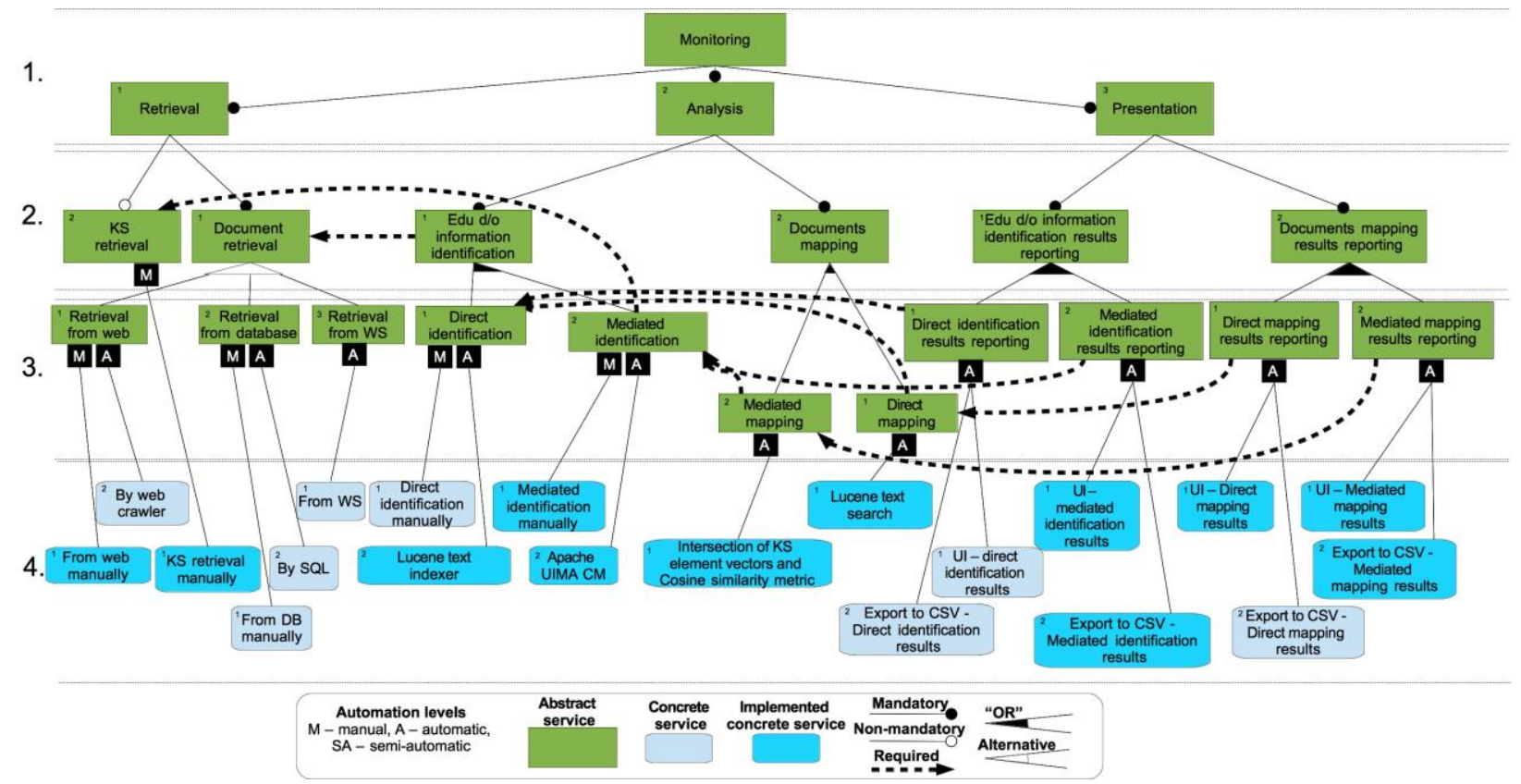

Figure 6. Feature model representing the view of EduMON functional variability. Concrete services are shown at level 4. Implemented concrete services are highlighted with the more intensive color. 
The EduMON behavioral variability view consists of intention-oriented service flows. Intention oriented services are formulated using the abstract services from the system's feature model. For instance, the service that achieves the intention "retrieve documents from Web resources and get the report of edu $\mathrm{d} / \mathrm{o}$ information source documents mediated mapping" is part of the EduMON behavior variability view as represented at the top of Figure 7 (A, 1.a) as $\operatorname{IS}_{(1.1 .1}$, 3.2.2). To design the service flows implementing this intention-oriented service, the EduMON feature model represented in Figure 6 was used and the IOSC method employed. An illustrative example of the result of the use of the IOSC method, representing the implementing service flows for the above-mentioned intention-oriented service, is given in Figure 7. More details about in intension oriented service engineering are available in [75].

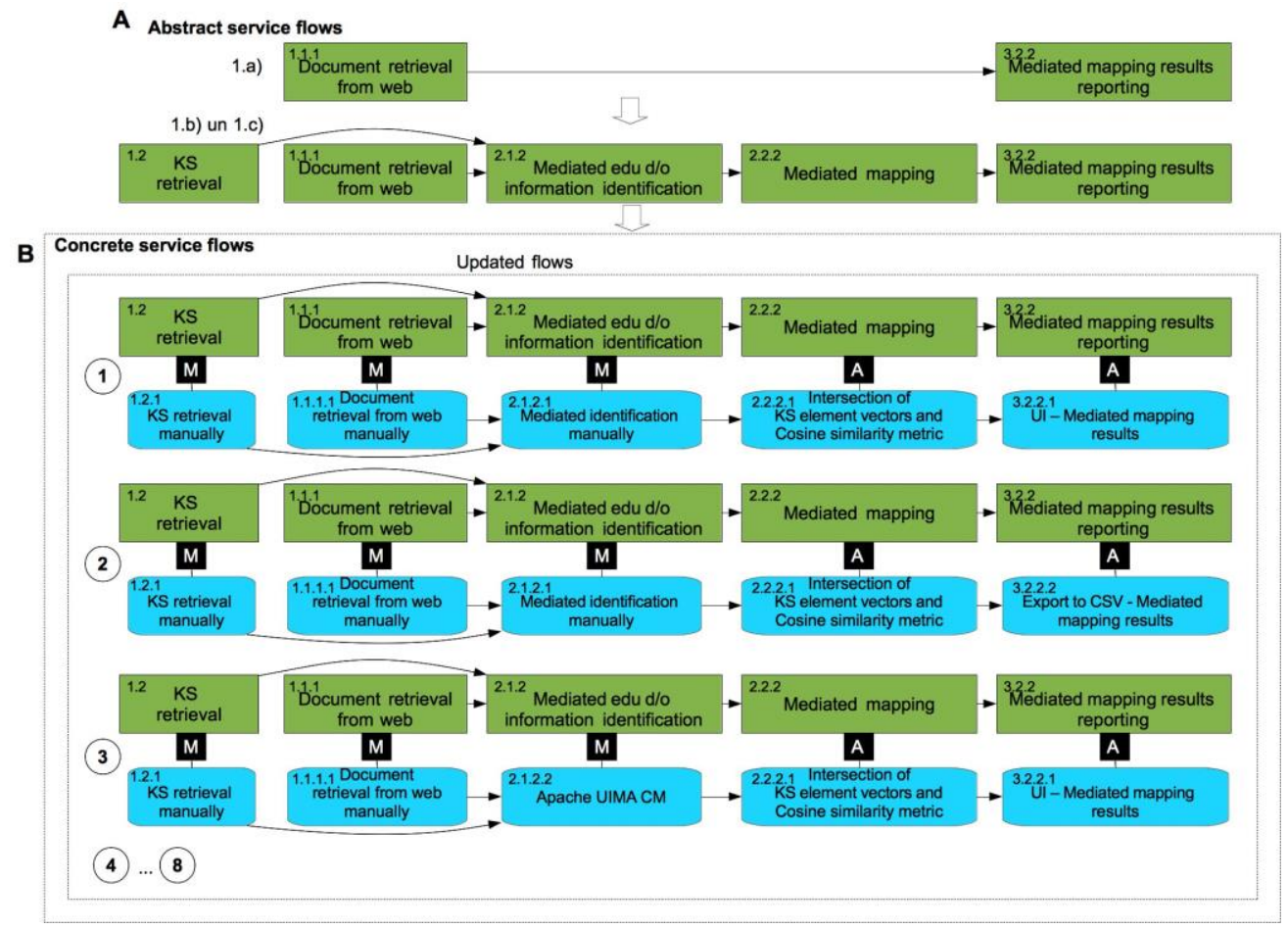

Figure 7. Examples of implemented service flows for intention-oriented service $\operatorname{IS}_{(1.1 .1 ; 3.2 .2)}$

The EduMON portal provided executable service flows consisting of the following services (the numbers of the services below in the text correspond to the numbers of the services in the boxes in Figure 7):

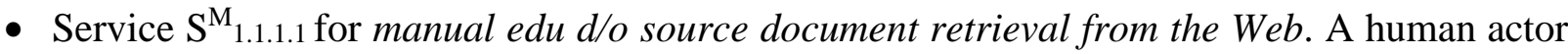
executes the service by visiting edu d/o information source and retrieving documents. After the retrieval, the documents are saved, e.g., in text files. To ensure the availability of the results of this service for other services, in EduMON, the user interface input form is implemented for entering them into the EduMON database.

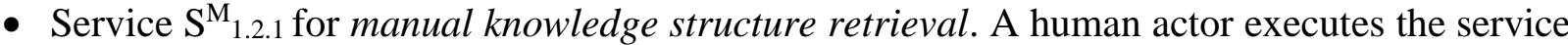
by visiting Web or other resources, where the knowledge structure of interest is reachable, and is retrieving this knowledge structure. After its retrieval the knowledge structure is saved, e.g., in the text file. To ensure the availability of the results of this service for other services, in EduMON, a special transition between the services is implemented, namely, the knowledge structure is transformed to the format acceptable for other services.

- Service $\mathrm{S}^{\mathrm{A}}{ }_{2.1 .2 .2}$ for mediated edu d/o information identification by using Apache UIMA platform. The service is executed by the Apache UIMA ConcepMapper [76] text analysis engine with the configuration adapted to enable the identification of knowledge structure elements in the documents. As the result of mediated edu $\mathrm{d} / \mathrm{o}$ information identification, the 
vector of knowledge structure elements (represented in the document) is created. The details of this service are described in [13] and [77].

- Service $\mathrm{S}^{\mathrm{A}}$ 2.1.1.2 for direct edu d/o information identification by text indexer and service $\mathrm{S}^{\mathrm{A}}{ }_{2.2 .1 .1}$ for direct edu d/o information source document mapping by text search. These services use text indexing and the Lucene search software library [78]. This library is integrated into the EduMON portal and it is used to perform the analysis of the edu $\mathrm{d} / \mathrm{o}$ source documents and to create the text index, and then to perform the search and comparison (i.e., document mapping) within this index.

- Service $\mathrm{S}^{\mathrm{A}}{ }_{2.2 .2 .1}$ for mediated edu d/o information source document mapping by using the vectors of knowledge structure elements and Cosine [79] similarity metric. The details of this service are described in [10].

- Presentation services for reporting:

- Services $\mathrm{S}^{\mathrm{A}}$ 3.1.2.1 and $\mathrm{S}^{\mathrm{A}}{ }_{3.1 .2 .2}$ for reporting the results of the mediated edu $\mathrm{d} / \mathrm{o}$ information identification via the user interface (UI) and by exporting them to CSV file format.

- Service $\mathrm{S}^{\mathrm{A}}$ 3.2.1.1 for reporting the results of the direct edu $\mathrm{d} / \mathrm{o}$ information source document mapping via UI.

- Services $\mathrm{S}^{\mathrm{A}}$ 3.2.2.1 and $\mathrm{S}^{\mathrm{A}}{ }_{3.2 .2 .2}$ for reporting the results of the mediated edu $\mathrm{d} / \mathrm{o}$ information source document mapping via UI and by exporting them to CSV file format.

\subsection{Evaluation of the GEduMON Model}

According to the design science research methodology the developed GEduMON model is the artifact. Analytical, experimental, testing, and descriptive methods can be used to evaluate artifacts [80]. Two of these descriptive methods, informed arguments and scenarios, were used to evaluate the GEduMON model. Information about the structure of the GEduMON model is used to make arguments about its suitability to the tackling of edu d/o information monitoring problems. For evaluation of model quality [81], usability of the model was evaluated by checking the model's conformance to requirements defined when stating the goal of the research in Section 2. The GEduMON model's practical utility was evaluated with scenarios, i.e., the EduMON portal usage scenarios were designed for demonstrating its utility.

\subsubsection{Usability of the GEduMON Model}

The GEduMON model was suitable to develop functional structure and behavioral variability models of the concrete monitoring system, namely, the EduMON portal, i.e., the proposed functional structure and behavioral variability models were usable to implement the software prototype (Figure 8).

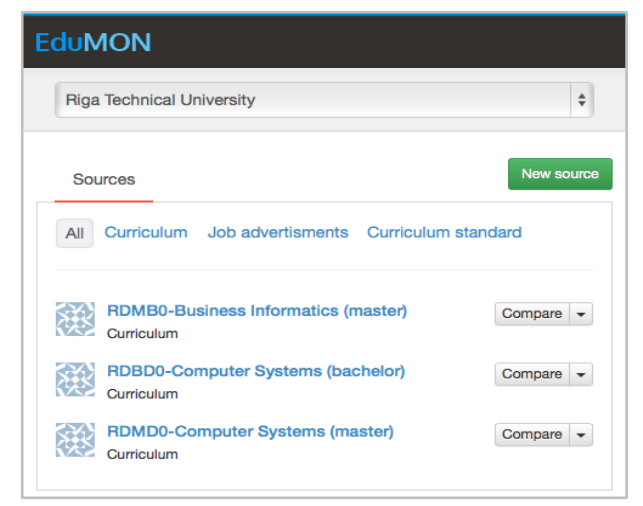

Figure 8. User interface of the EduMON portal 
The EduMON portal was designed and implemented by extending the GEduMON functional structure and behavior variability models with concrete services. The services for knowledge structure retrieval, edu d/o information source document retrieval, direct and mediated edu d/o information identification and document mapping, and the services for presenting the results of the identification and mapping were implemented in the EduMON portal. Table 1 shows how the EduMON portal fulfills the edu d/o monitoring requirements stated in Section 2.

Table 1. Requirements satisfied by the implemented EduMON portal

\begin{tabular}{|c|l|}
\hline Requirement & \multicolumn{1}{|c|}{ EduMON portal } \\
\hline Req. 1 & $\begin{array}{l}\text { The services provided by the EduMON portal enable to process diverse types and large amount of } \\
\text { edu d/o information source documents retrieved from different locations (e.g., job advertisements, } \\
\text { course descriptions that are available on the Web and internal databases) and identify the } \\
\text { compliance between edu d/o information source documents. The analysis services can process also } \\
\text { unstructured text documents, which is more complex task than processing structured and semi- } \\
\text { structured documents. }\end{array}$ \\
\hline Req. 2 & $\begin{array}{l}\text { Multiple stakeholders (e.g., teachers, representatives of companies, system maintainers, etc) can } \\
\text { access the EduMON portal, execute the transitions between services and use the results provided by } \\
\text { the services. }\end{array}$ \\
\hline Req. 3 & $\begin{array}{l}\text { The services with different automation levels are implemented. The implementation variants of } \\
\text { services are represented in the EduMON functional structure and behavioral variability models. }\end{array}$ \\
\hline
\end{tabular}

Taking into account that the EduMON portal is designed and developed on the basis of the GEduMON model, thus, satisfying edu d/o monitoring requirements for processing edu $\mathrm{d} / \mathrm{o}$ information with various characteristics, involvement of various stakeholders in the system, and satisfying the requirements for various implementation variants of activities with different levels of automation, the GEduMON model was found usable for the design and implementation of edu d/o monitoring systems.

\subsubsection{Utility of the GEduMON Model}

The practical utility of the GEduMON model was evaluated by using its implementation - the EduMON portal, in running two scenarios for the achievement of stakeholder goals, namely, the scenario of continuous edu d/o source document monitoring and the scenario for continuous monitoring of compliance between edu $\mathrm{d}$ and edu $\mathrm{o}$.

Scenario 1 - monitoring edu d/o source documents. A study program director responsible for a curriculum wants to identify the knowledge demand for the software developers. To achieve this goal, the concrete service flows of intention-oriented service $\operatorname{IS}_{(1.1 .1 .3 .1 .2)}$ (Figure 7) was used. This intention-oriented service, which invokes a number of other services, is predefined for retrieving documents from the Web resources and getting the report of mediated edu $\mathrm{d} / \mathrm{o}$ information identification. In this scenario we used the following service flow: $S^{M_{1.2 .1}}, S^{M_{1.1 .1 .1}}$, $\mathrm{S}^{\mathrm{A}}$ 2.1.2.2, $\mathrm{S}^{\mathrm{A}}{ }_{3.2 .2 .2}$, where edu $\mathrm{d} / \mathrm{o}$ source documents were manually retrieved from the Web, mediated edu $\mathrm{d} / \mathrm{o}$ information identification was performed by Apache UIMA (by using 3 knowledge structures - ACM-CCS, DISCO and ONET), and the identification results were presented by exporting them into CSV file format. Exporting to CSV file format enabled more extensive analysis of identified edu d/o information in spreadsheet software (e.g., MS Excel or LibreOffice Calc), where the use of pivot tables is possible.

The knowledge demand for software developers is represented in job advertisements. Thus, from the job advertisement portal Https//:cv.lv, 85 job advertisements on software developer positions were obtained manually (EduMON service $\mathrm{S}^{\mathrm{M}_{1.1 .1 .1}}$ was performed; software developer positions were identified in the advertisements that included text units "developer", "programmer", "software engineer" or "software architect" in the title). After invoking other services, the identified edu d/o information was represented in the EduMON portal (presentation 
service $\mathrm{S}^{\mathrm{A}}{ }_{3.1 .2 .1}$ for reporting the results of mediated edu $\mathrm{d} / \mathrm{o}$ information identification via UI), though, for further interpretation, the results were exported to a CSV file and the analysis was done using MS Excel spreadsheet pivot table reporting functionality.

The services provided by the EduMON portal supported the reporting of identified edu $\mathrm{d} / \mathrm{o}$ information, thus allowing interpretation of the identification results by using pivot functionality in spreadsheet software. In this scenario, the results of edu $\mathrm{d} / \mathrm{o}$ information identification in software developer job advertisements were obtained and interpreted (Figure 8). It was concluded that $61 \%$ of selected job advertisements demand knowledge of the English language, $34 \%$ - knowledge of the JavaScript language, 32\% - knowledge of the programming language Java, 31\% - knowledge of the data management system MySQL. The experiment was run in 2015. At this time the course on Java was not included in the curriculum, based on the assumption that teaching some other programming languages gives better long-term results in terms of students' software engineering knowledge. Nevertheless, following discussions with the industry, after a couple of years the curriculum was changed, and Java courses included in it. By 2021 no decline in software engineering knowledge of students has been observed. The frequency of running such a scenario is not restricted by the EduMON portal, thus the GEduMON model supports continuous curriculum engineering.

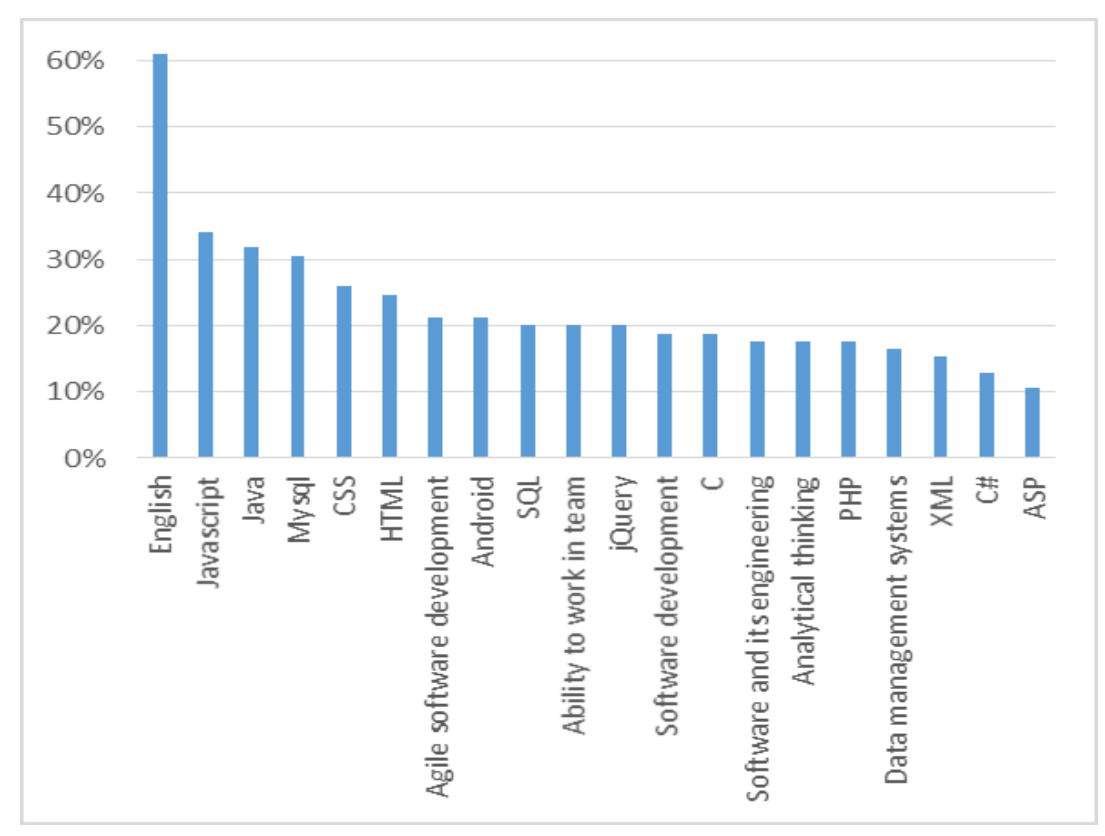

Figure 9. The results of mediated (via knowledge structures) document analysis (Y-axis: the percentage of job advertisements that include a knowledge structure element represented on the $\mathrm{X}$ axis)

Scenario 2 - monitoring edu d/o source document mapping (comparing these documents): A bachelor level study program's "Computer Systems" director wants to determine the compliance of the curriculum courses with the job advertisements posted by the company Accenture Ltd. In total, 10 job advertisements and 85 study courses were to be analyzed. This scenario was implemented by concrete service flows of intention-oriented service $\operatorname{IS}_{(1.1 .1 .3 .2 .2)}$ (Figure 7). This service invokes other services for retrieving documents from Web resources and getting the report of mediated edu $\mathrm{d} / \mathrm{o}$ information source document mapping. In this scenario, we considered the service flow where edu $\mathrm{d} / \mathrm{o}$ information source documents were manually retrieved from the Web, mediated edu $\mathrm{d} / \mathrm{o}$ information identification was performed by Apache UIMA, mediated edu d/o information source document mapping was performed by using knowledge structure element vectors, and the result of the mapping was presented by exporting it to a CSV file. The report of the results of mediated edu $\mathrm{d} / \mathrm{o}$ information source document mapping, represented via UI of the EduMON portal, is shown in Figure 9. 
The report represented in Figure 9 did not provide extended analysis of mapping results. To perform detailed mapping analysis, the service for exporting results to a CSV file was used. Then, using spreadsheet software and pivot table reporting functionality, the mapping results were analyzed to see exactly which knowledge structure elements of advertisements were, or were not, covered by which courses of the curriculum.

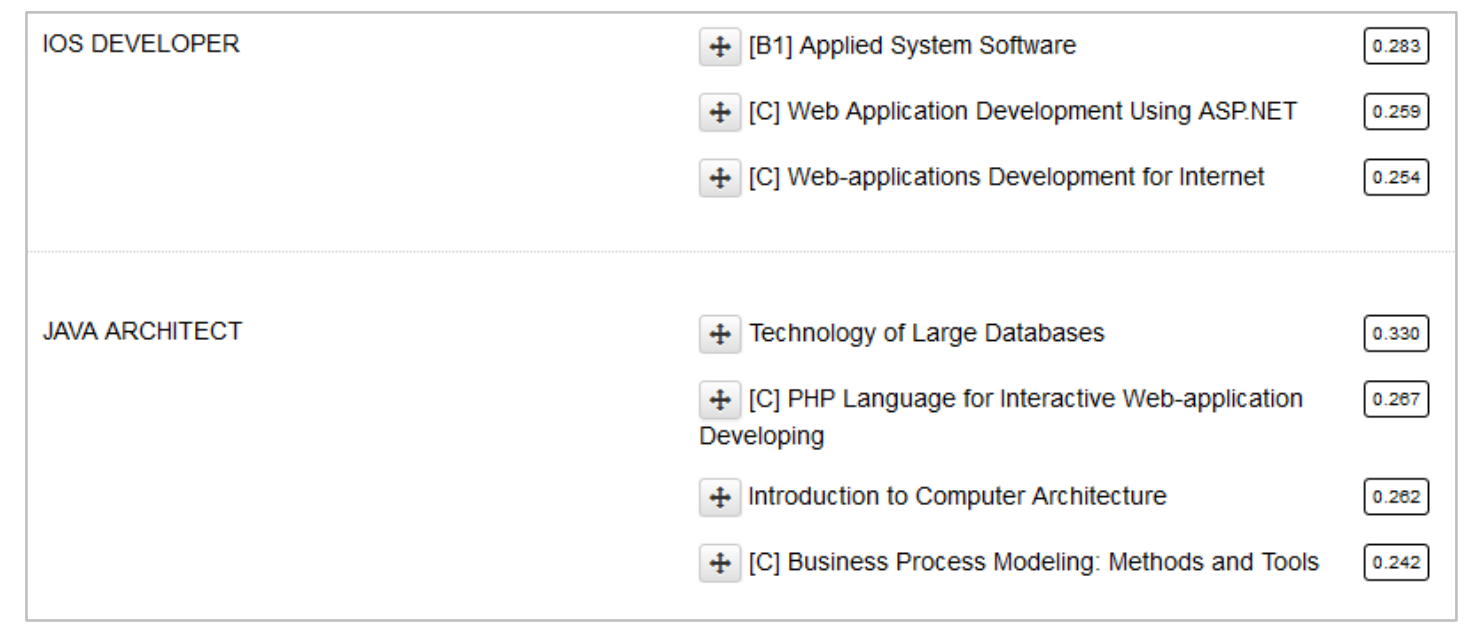

Figure 10. Fragment of the result of EduMON presentation service - the compliance between courses of "Computer Systems" curriculum and Accenture Ltd. job advertisements

Services provided by the EduMON portal supported continuous representation of the results of edu d/o source document mapping (comparison), thus allowing the continuous interpretation of these results by using pivot reporting functionality in spreadsheet software.

\section{Discussion and Conclusion}

Today, curriculum development and maintenance, as does any enterprise, faces the necessity for continuous adjustments to comply with industrial needs and scientific advances. Therefore, in the era of artificial intelligence, continuous curriculum engineering becomes an achievable target for modern educational institutions. Continuity in engineering implies availability of means for monitoring the objects of interest in order to identify the need for changes. This article shows how a system for monitoring compliance between educational demand and offer can be designed and implemented. The system was implemented by 2015 and showed high utility. However, its usability gradually deteriorated, due to changes in the software platforms that were used in its implementation and, also, because of a relatively high amount of manual work which was necessary to use and maintain the system.

The system was designed to be flexible, because of diversity of document types to be processed and variety of potential stakeholders. It was also accepted that not all tasks will be possible to run solely by software components. Therefore, three modes of service execution (manual, semi-automatic, and automatic) were introduced in the proposed generic monitoring systems (GEduMON) model. While all these modes were important in running the monitoring system's prototype EduMON, the establishment and maintenance of interfaces between the services of different modes were perceived as time consuming and monotonous functions. Therefore, in their further development, attention should be paid to possibilities of automating these functions to a higher extent. Nonetheless, the concept of a monitoring system, as a service system, proved to be correctly chosen, because the EduMON portal could be used with a high degree of flexibility, thus supporting the needs of continuous curriculum engineering.

As the spectrum of source documents for monitoring is not restricted, the documents from scientific databases can also be processed by the monitoring system, thus providing a possibility 
to monitor curriculum compliance, not only against industry needs, but also the advances in scientific areas that are relevant to the curriculum.

The monitoring of curriculum compliance is just one of the tasks of continuous curriculum engineering. However, even the fulfillment of this one task requires quite sophisticated software support as is shown by the GEduMON model. Therefore, we can conclude that, in further research, the software support for curriculum engineering should be designed on the basis of a continuous software engineering paradigm that is compatible with continuous curriculum engineering.

\section{References}

[1] K. Kosanke, F. B. Vernadat, and M. Zelm, "Enterprise Engineering and Integration in the Global Environment," Advances in Networked Enterprises. BASYS 2000. IFIP - The International Federation for Information Processing, vol. 53. Springer, pp. 61-70, 2000. Available: https://doi.org/10.1007/978-0-38735529-0_6

[2] C. Romero and S. Ventura, "Educational data mining and learning analytics: An updated survey," WIREs Data Mining and Knowledge Discovery, vol.10, no.3, 2020. Available: https://doi.org/10.1002/widm.1355

[3] M. Somasundarama, P. Lathab, and S. A.Saravana Pandianc, "Curriculum Design Using Artificial Intelligence (AI) Back Propagation Method," Procedia Computer Science, vol. 172, pp. 134-138, 2020. Available: https://doi.org/10.1016/j.procs.2020.05.020

[4] F. Falcone, P. Sanchis, A. Lopez-Martin, M. P. Milagros, and A. Alejos, "The role of university-industry liaisons in achieving comprehensive curricula in engineering," 2014 IEEE Global Engineering Education Conference (EDUCON), 2014, pp. 519-522. Available: https://doi.org/10.1109/EDUCON.2014.6826141

[5] M. O. Ahmad, K. Liukkunen, and J. Markkula, "Student perceptions and attitudes towards the software factory as a learning environment," 2014 IEEE Global Engineering Education Conference (EDUCON), 2014, pp. 422-428. Available: https://doi.org/10.1109/EDUCON.2014.6826129

[6] P. Thompson and D. Surgeoner, "Bridging the gap: university to professional qualifications," Proceedings of the ICE - Management, Procurement and Law, vol. 167, no. 4, pp. 189-200, Aug. 2014. Available: https://doi.org/10.1680/mpal.13.00034

[7] R. Strazdina and M. Kirikova, "Interaction model supporting collaboration between university and industry," EDULEARN09 Proceedings, pp. 4879-4885, 2009.

[8] P. Rudzajs and M. Kirikova, "IT Knowledge Requirements Identification In Organizational Networks : Cooperation Between Industrial Organizations And Universities," Information Systems Development: Asian Expierences, W. W. Song, S. Xu, C. Wan, Y. Zhong, W. Wojtkowski, G. Wojtkowski, and H. Linger, Eds. Springer, pp. 187-199, 2011. Available: https://doi.org/10.1007/978-1-4419-7355-9_16

[9] K. Peffers, T. Tuunanen, M. A. Rothenberger, and S. Chatterjee, "A Design Science Research Methodology for Information Systems Research,” Journal of Management Information Systems, vol. 24, no. 3, pp. 45-77, 2008. Available: https://doi.org/10.2753/MIS0742-1222240302

[10] P. Rudzajs and M. Kirikova, "Mediated competency comparison between job descriptions and university courses," Applied Computer Systems, vol. 47, pp. 48-56, 2011.

[11] P. Rudzajs, L. Penicina, M. Kirikova, and R. Strazdina, "Towards Narrowing a Conceptual Gap Between IT Industry and University," Applied Computer Systems, vol. 43, pp. 9-16, 2010.

[12] P. Rudzajs, M. Kirikova, R. Strazdina, and U. Sukovskis, "Learning outcomes in the mirror of qualification frameworks," The 3rd International Conference: Institutional Strategic Quality Management - ISQM 2011, pp. 247-254, 2011.

[13] P. Rudzajs, "Towards automated education demand-offer information monitoring: The Information Extraction," Sixth International Conference on on Research Challenges in Information Science (RCIS 2012), pp. 453-454, 2012. Available: https://doi.org/10.1109/RCIS.2012.6240464

[14] P. Rudzajs, "Towards Automated Education Demand-Offer Information Monitoring: the System's Architecture," Lecture Notes in Business Information Processing (Workshops on Business Informatics Research), L. Niedrite, R. Strazdina, and B. Wangler, Eds. Springer, pp. 252-265, 2012. Available: https://doi.org/10.1007/978-3-642-29231-6_20

[15] P. Rudzajs, M. Kirikova, and R. Strazdina, "Capabilities and Challenges of Contemporary Service Based Monitoring Systems," Lecture Notes in Business Information Processing (Perspectives in Business Informatics Research), vol. 158, A. Kobyliński and A. Sobczak, Eds. Warsaw, Poland: Springer, pp. 278-289, 2013. Available: https://doi.org/10.1007/978-3-642-40823-6_22 
[16] P. Rudzajs and M. Kirikova, "Enhancing Knowledge Flow by Mediated Mapping Between Conceptual Structures," Third International Conference on Information, Process, and Knowledge Management, pp. 3641, 2011.

[17] R. Strazdina, M. Kirikova, L. Penicina, and P. Rudzajs, "Knowledge Requirements Monitoring System: Advantages for Industry and University," Second International Conference on Information, Process, and Knowledge Management, pp. 120-125, 2010. Available: https://doi.org/10.1109/eKNOW.2010.22

[18] P. Rudzajs, M. Kirikova, and R. Strazdina, "Configurative Alignment of Business and Application Services: A Work Systems Perspective," Lecture Notes in Business Information Processing (Business Information Systems), Springer, pp. 100-111, 2013. Available: https://doi.org/10.1007/978-3-642-41687-3_11

[19] M. Kirikova and P. Rudzajs, "Multimode Information Logistics for Conceptual Correspondence Monitoring," 5th Workshop on Information Logistics and Knowledge Supply (held in conjunction with BIR2012), pp. 31-42, 2012.

[20] P. Rudzajs and M. Kirikova, "Multimode Information Logistics in Conceptual Correspondence Monitoring," Complex Systems Informatics and Modeling Quarterly (CSIMQ), vol. 1, no. 1, pp. 57-73, 2014. Available: https://doi.org/10.7250/csimq.2014-1.04

[21] P. Rudzajs and M. Kirikova, "Variability Handling in Multi-Mode Service Composition," Proceedings of 2nd International Conference on the Human Side of Service Engineering, pp. 1-10, 2014.

[22] P. Rudzajs and M. Kirikova, "Service Functioning Mode in Variability Model," Lecture Notes in Business Information Processing (Advanced Information Systems Engineering Workshops), vol. 178, L. Iliadis, M. Papazoglou, and K. Pohl, Eds. Springer, pp. 124-135, 2014. Available: https://doi.org/10.1007/978-3-31907869-4_11

[23] J. L. G.Dietz, J. A. P. Hoogervorst, A. Albani, D. Aveiro, E. Babkin, J. Barjis, A. Caetano, P. Huyments, J. Iijima, S. J. H. Van Kervel, H. Mulder, M. Op't Land, H. A. Proper, J. Sanz, L. Terlouw, J. Tribolet, J. Verelst, R. Winter, "The Discipline of Enterprise Engineering," International Journal of Organisation Design and Engineering, vol. 3, no. 1, pp. 86-114, 2013. Available: https://doi.org/10.1504/IJODE.2013.053669

[24] P. Rao and K. Palaniappan K. "Continuous Engineering Through ALM-PLM Integration," Nyffenegger F., Ríos J., Rivest L., Bouras A. (eds) Product Lifecycle Management Enabling Smart X. PLM 2020. IFIP Advances in Information and Communication Technology, vol. 594. Springer, 2020. Available: https://doi.org/10.1007/978-3-030-62807-9_62

[25] B. Liu, Web Data Mining. Springer, 2011. Available: https://doi.org/10.1007/978-3-642-19460-3

[26] S. H. Rubin and S.-C. Chen, "The 2013 IEEE International conference on information reuse and integration: Forward," 2013 IEEE 14th International Conference on Information Reuse \& Integration (IRI), pp. xii-xii, 2013. Available: https://doi.org/10.1109/IRI.2013.6642432

[27] R. Parasuraman, T. B. Sheridan, and C. D. Wickens, "A model for types and levels of human interaction with automation.," IEEE transactions on systems, man, and cybernetics. Part A, Systems and humans: a publication of the IEEE Systems, Man, and Cybernetics Society, vol. 30, no. 3, pp. 286-97, 2000. Available: https://doi.org/10.1109/3468.844354

[28] R. Patton and P. Patton, "What can be automated? What cannot be automated?," Handbook of Automation, Springer, pp. 305-313, 2009. Available: https://doi.org/10.1007/978-3-540-78831-7_18

[29] A. Sasa, M. B. Juric, and M. Krisper, "Service-Oriented Framework for Human Task Support and Automation," IEEE Transactions on Industrial Informatics, vol. 4, no. 4, pp. 292-302, 2008. Available: https://doi.org/10.1109/TII.2008.2008641

[30] K. F. Vajargah and S. Jahani, "Application of ICT in University Curriculum Development," 2009 International Conference on Education Technology and Computer, pp. 60-64, 2009. Available: https://doi.org/10.1109/ICETC.2009.74

[31] E. G. S. Watson, P. J. Moloney, S. M. Toohey, C. S. Hughes, S. L. Mobbs, J. B. Leeper, and H. P. McNeil, "Development of eMed: a comprehensive, modular curriculum-management system," Academic medicine: Journal of the Association of American Medical Colleges, vol. 82, no. 4, pp. 351-60, 2007. Available: https://doi.org/10.1097/ACM.0b013e3180334d41

[32] J. E. Hoch and J. H. Dulebohn, "Shared leadership in enterprise resource planning and human resource management system implementation," Human Resource Management Review, vol. 23, no. 1, pp. 114-125, 2013. Available: https://doi.org/10.1016/j.hrmr.2012.06.007

[33] D. Soergel, "The rise of ontologies or the reinvention of classification," Journal of the American Society for Information Science, vol. 50, no. 12, pp. 1119-1120, 1999. Available: https://doi.org/10.1002/(SICI)10974571(1999)50:12<1119::AID-ASI12>3.0.CO;2-I 
[34] M. Asgrahani and V. Shankararaman, "Skills frameworks: A tool for reform in Information Technology higher education," 9th International Conference on Computer Science \& Education, pp. 81-88, 2014. Available: https://doi.org/10.1109/ICCSE.2014.6926434

[35] M. Vrang, A. Papantoniou, E. Pauwels, P. Fannes, D. Vandensteen, and J. De Smedt, "ESCO: Boosting Job Matching in Europe with Semantic," Computer, vol. 47, no. 10, pp. 57-64, 2014. Available: https://doi.org/10.1109/MC.2014.283

[36] European Commission, "European Interoperability Framework (EIF) Promoting seamless services and data flows for European public administrations," $E U$ (2017), pp. 1-48, $2017 . \quad$ Available: https://ec.europa.eu/isa2/sites/default/files/eif_brochure_final.pdf

[37] "Association for Computing Machinery (ACM) taxonomy," 2012. Available: http://www.acm.org/about/class/2012

[38] H. Müller-Riedlhuber, "The european dictionary of skills and competences (DISCO): An example of usage scenarios for ontologie," Proceedings of I-KNOW 2009 - 9th International Conference on Knowledge Management and Knowledge Technologies and Proceedings of I-SEMANTICS 2009 - 5th International Conference on Semantic Systems, pp. 467-479, 2009.

[39] IT Professionalism Europe. Available: https://itprofessionalism.org/

[40] Occupational Information Network, "Onet resource center." Available: http://www.onetcenter.org/supplemental.html

[41] H. Cunningham, "Information Extraction, Automatic," Science, vol. 5, no. November, pp. 1-22, 2004.

[42] D. FerruccI and A. Lally, "UIMA: an architectural approach to unstructured information processing in the corporate research environment," Natural Language Engineering, vol. 10, no. 3-4. pp. 327-348, 2004. Available: https://doi.org/10.1017/S1351324904003523

[43] H. Cunningham, "GATE, a general architecture for text engineering," Computers and the Humanities, vol. 36, no. 2, pp. 223-254, 2002. Available: https://doi.org/10.1023/A:1014348124664

[44] V. Janev, V. Mijović, and S. Vraneš, “Automatic Extraction of ICT Competences from Unstructured Sources,” ENTERprise Information Systems, vol. 110, J. E. Quintela Varajão, M. M. Cruz-Cunha, G. D. Putnik, and A. Trigo, Eds. Springer, pp. 391-400, 2010. Available: https://doi.org/10.1007/978-3-642-16419-4_40

[45] Princeton University, “About WordNet,” 2010. Available: http://wordnet.princeton.edu

[46] F. Li, K. Huang, B. Yang, H. Wang, Z. Dai, and H. Ma, "Research on SOA-Based Education Resource Service System," 2008 Second International Conference on Genetic and Evolutionary Computing, pp. 427-430, 2008. Available: https://doi.org/10.1109/WGEC.2008.111

[47] Y. Schikhof, I. Mulder, and S. Choenni, "Who will watch (over) me? Humane monitoring in dementia care," International Journal of Human-Computer Studies, vol. 68, no. 6, pp. 410-422, 2010. Available: https://doi.org/10.1016/j.ijhcs.2010.02.002

[48] P. Phillips and D. Diston, "A knowledge driven approach to aerospace condition monitoring," KnowledgeBased Systems, vol. 24, no. 6, pp. 915-927, 2011. Available: https://doi.org/10.1016/j.knosys.2011.04.008

[49] B. Krishnamurthy, "A Top Down Approach to Enterprise Monitoring Using Change Point Detection," 2012 Annual SRII Global Conference, pp. 859-862, 2012. Available: https://doi.org/10.1109/SRII.2012.96

[50] M. Kaschesky, P. Sobkowicz, J. M. Hernandez Lobato, G. Bouchard, C. Archambeau, N. Scharioth, R. Manchin, A. Gschwend, and R. Riedl, "Bringing Representativeness into Social Media Monitoring and Analysis," 2013 46th Hawaii International Conference on System Sciences, pp. 2003-2012, 2013. Available: https://doi.org/10.1109/HICSS.2013.120

[51] F. Johansson, J. Brynielsson, and M. N. Quijano, "Estimating Citizen Alertness in Crises Using Social Media Monitoring and Analysis," 2012 European Intelligence and Security Informatics Conference, pp. 189-196, 2012. Available: https://doi.org/10.1109/EISIC.2012.23

[52] B. Kang, D. Kim, and S.-H. Kang, "Real-time business process monitoring method for prediction of abnormal termination using KNNI-based LOF prediction," Expert Systems with Applications, vol. 39, no. 5, pp. 60616068, 2012. Available: https://doi.org/10.1016/j.eswa.2011.12.007

[53] L. Carrizo, C. Sauvageot, and N. Bella, Information tools for the preparation and monitoring of education plans, no. 5. 2003.

[54] D. Wagner, B. Day, and T. James, Monitoring and evaluation of ICT in education projects. A handbook for developing countries. Washington, DC: infoDev / World Bank, 2005.

[55] F. Rodrigues and P. Oliveira, "A system for formative assessment and monitoring of students' progress," Computers \& Education, vol. 76, pp. 30-41, 2014. Available: https://doi.org/10.1016/j.compedu.2014.03.001

[56] A. Avotiņš, "Monitoringa sistēmu lietojums mēdiju monitoringā,” B. S. thesis, Riga Technical University, 2014 (in Latvian). 
[57] T. Erl, SOA Principles of Service Design. Prentice Hall PTR, 2008.

[58] J. Spohrer, P. Maglio, J. Bailey, and D. Gruhl, "Steps Toward a Science of Service Systems," Computer, vol. 40, no. 1, pp. 71-77, 2007. Available: https://doi.org/10.1109/MC.2007.33

[59] S. Alter, "Viewing systems as services: a fresh approach in the IS field," Communications of the Association for Information Systems, vol. 26, no. 11, pp. 195-224, 2010. Available: https://doi.org/10.17705/1CAIS.02611

[60] J. Spohrer, H. Demirkan, and V. Krishna, "Service and Science," The Science of Service Systems, H. Demirkan, J. C. Spohrer, and V. Krishna, Eds. Boston, Springer, 2011. Available: https://doi.org/10.1007/978$1-4419-8270-4$

[61] C. Ba, U. Costa, M. Halfeld-ferrari, M. A. Musicante, V. Peralta, and S. Robert, "Preference-Driven Refinement of Service Compositions," CLOSER, 4th International Conference on Cloud Computing and Services Science, pp. 268-275, 2013.

[62] M. Galster, D. Weyns, D. Tofan, B. Michalik, and P. Avgeriou, "Variability in Software Systems - A Systematic Literature Review," IEEE Transactions on Software Engineering, vol. 40, no. 3, pp. 282-306, 2014. Available: https://doi.org/10.1109/TSE.2013.56

[63] T. Nguyen, A. Colman, M. Talib, and J. Han, "Managing service variability: state of the art and open issues," Proceedings of the 5th Workshop on Variability Modeling of Software-Intensive Systems, pp. 165-173, 2011. Available: https://doi.org/10.1145/1944892.1944913

[64] K. C. Kang and H. Lee, "Variability Modeling," Systems and Software Variability Management: Concepts, Tools and Experiences, R. Capilla, J. Bosch, and K.-C. Kang, Eds. Springer, pp. 25-42, 2013. Available: https://doi.org/10.1007/978-3-642-36583-6_2

[65] M. Galster, P. Avgeriou, T. Männistö, and D. Weyns, "Variability in Software Architecture - State of the Art," Journal of Systems and Software, vol. 91, pp. 1-2, 2014. Available: https://doi.org/10.1016/j.jss.2014.01.051

[66] J. van Gurp, J. Bosch, and M. Svahnberg, "On the notion of variability in software product lines," Proceedings of the Working IEEE/IFIP Conference on Software Architecture, pp. 45-54, 2001.

[67] M. Svahnberg, J. van Gurp, and J. Bosch, “A Taxonomy of Variability Realization Techniques: Research Articles," Softw. Pract. Exper., vol. 35, no. 8, pp. 705-754, 2005. Available: https://doi.org/10.1002/spe.652

[68] J. Ralyté, A. Khadraoui, and M. Léonard, "From Information Systems to Information Services Systems: Designing the Transformation," The Practice of Enterprise Modeling, vol. 165, J. Grabis, M. Kirikova, J. Zdravkovic, and J. Stirna, Eds. Springer, pp. 69-84, 2013. Available: https://doi.org/10.1007/978-3-64241641-5_6

[69] K. C. Kang, S. G. Cohen, J. A. Hess, W. E. Novak, and A. S. Peterson, Feature-oriented domain analysis (FODA) feasibility study. Technical Report, 1990.

[70] P. Sochos, M. Riebisch, and I. Philippow, "The feature-architecture mapping (FArM) method for featureoriented development of software product lines," 13th Annual IEEE International Symposium and Workshop on Engineering of Computer-Based Systems (ECBS'06), pp. 9-318, 2006. Available: https://doi.org/10.1109/ECBS.2006.69

[71] K. Petersen, N. Bramsiepe, and K. Pohl, “Applying Variability Modeling Concepts to Support Decision Making for Service Composition," Service-Oriented Computing: Consequences for Engineering Requirements, 2006. SOCCER '06, pp. 1-1, 2006. Available: https://doi.org/10.1109/SOCCER.2006.1

[72] N. Rozanski and E. Woods, "Applying Viewpoints and Views to Software Architecture," Available: https://www.viewpoints-and-perspectives.info/, 2005.

[73] B. Tekinerdogan and H. Sözer, "Variability viewpoint for introducing variability in software architecture viewpoints," Proceedings of the WICSA/ECSA 2012 Companion Volume on - WICSA/ECSA '12, pp. 163-166, 2012. Available: https://doi.org/10.1145/2361999.2362033

[74] H. Jaakkola and B. Thalheim, “Architecture-Driven Modelling Methodologies," Proceedings of the 2011 conference on Information Modelling and Knowledge Bases XXII, vol. XXII, pp. 97-116, 2011.

[75] C. Rolland, M. Kirsch-Pinheiro, and C. Souveyet, "An intentional approach to service engineering," IEEE Transactions on Service Computing, vol. 3, no. 4, pp. 292-305, 2010. Available: https://doi.org/10.1109/TSC.2010.26

[76] M. Tanenblatt, A. Coden, and I. Sominsky, "The conceptmapper approach to named entity recognition," LREC Conference, Malta, pp. 546-551, 2010.

[77] P. Rudzājs, "Problēmspecifisku datu izgūšana no dokumentiem, izmantojot dažādas zināšanu struktūras (Valsts pētījumu programmas projekta uzdevuma atskaite)," 2012 (in Latvian).

[78] A. Bialecki, R. Muri, and G. Ingersoll, “Apache Lucene 4," Proceedings of the SIGIR 2012 Workshop on Open Source Information Retrieval, pp. 17-24, 2012. 
[79] A. Huang, "Similarity Measures for Text Document Clustering," Proceedings of the New Zealand Computer Science Research Student Conference, 2008.

[80] A. Hevner, S. March, J. Park, and S. Ram, "Design science in information systems research," MIS quarterly, no. 520, 2004. Available: https://doi.org/10.2307/25148625

[81] M. Wieczorek, D. Vos, and H. Bons, "How Can We Implement a Framework for Right Quality?" Systems and Software Quality, Springer, pp. 97-126, 2014. Available: https://doi.org/10.1007/978-3-642-39971-8_5 